\title{
Projeto Oficinas Técnico-Científicas para o ensino tecnológico
}

\section{Project Technical-Scientific Workshops for technological education}

Ana Beatriz Ramos Moreira Abrahão, Monica Franchi Carniello, Claudete Oliveira Kenvyn, Wiliam Gonzaga Pereira, Carlos Eduardo Figueiredo Santos, Joana Toledo Guimarães*

\section{RESUMO}

Este trabalho, "Oficinas técnico-científicas", tem por objetivo promover atividades diferenciadas baseadas em metodologias ativas que estimulem os alunos a dar continuidade aos estudos, motivando-os por meio de atividades adicionais e práticas desenvolvidas em oficinas extraclasses e, dessa maneira, proporcionando maior interesse e estímulo aos estudos de forma a contribuir para a diminuição da evasão. As atividades relacionadas ao projeto inicialmente focaram na implantação e estavam direcionadas para os cursos que mais apresentam problemas de evasão e baixa formação de concluintes (tecnologia em mecânica: processos de soldagem e tecnologia em projetos mecânicos). Foram divididas em quatro oficinas que visaram o desenvolvimento de habilidades específicas de natureza prática: a) conceitos básicos de soldagem para utilização de laboratório; b) utilização do Laboratório de química e preparo de soluções; c) terminologia de soldagem em inglês (English terminology) e; 4) estudo de software educativo (Aprendendo a manipular a calculadora científica). As oficinas tiveram como público alvo os discentes de todos os cursos e semestres da Faculdade de Tecnologia de Pindamonhangaba que puderam optar por fazer quantas oficinas fossem de seu interesse e disponibilidade.

Palavras-chave: Oficina Técnico-Científica, Metodologias ativas, Soldagem.

\begin{abstract}
The project "Technical-scientific workshops" purpose is to promote differentiated activities based on active methodologies that stimulate students to continue their studies, motivating them through additional activities and practices developed in extra class workshops and, consequently, to provide greater interest and encouragement to the studies also contributing to the reduction of circumvention. The activities related to the project directed initially for the implantation and also to the courses that presented more problems of evasion and small amount of formation of graduates (Technology in mechanics: processes of welding and Technology in mechanical designs), form divided in four workshops that aimed at the development of specific skills of a practical nature. They are: a) basic concepts of welding for laboratory use; b) use of the chemical laboratory and preparation of solutions; c) welding terminology in English; 4) Educational software study: learning to manipulate the scientific calculator. The workshops had as target audience the students of all courses and semesters of Fatec Pindamonhangaba, who could choose to make as many workshops as they could of their interest and availability.
\end{abstract}

Key words: Technical-Scientific Workshop, Active methodologies, Welding. 


\section{INTRODUÇÃO}

Este projeto surgiu devido à preocupação com o número de alunos que não concluem o curso, abandonando a faculdade antes mesmo do terceiro semestre ${ }^{1,2}$. Com o intuito de estimulálos a concluir o curso, surgiu a ideia do desenvolvimento das atividades extraclasses, ou seja, as oficinas, como tentativa de estimular e motivar o corpo discente e, ao mesmo tempo, conter a evasão.

As oficinas promovem atividades que tem por base metodologias ativas. Tais metodologias, segundo o Ministério da Educação ${ }^{1,2}$, ocorrem quando o aluno interage com o assunto em estudo, ouvindo, falando, perguntando, discutindo, fazendo e ensinando, ou seja, sendo estimulado a construir o que aprende, ao contrário da metodologia tradicional, na qual ele apenas recebe passivamente o conteúdo do Prof.. Em um ambiente de metodologia ativa, o Prof. atua como orientador, supervisor e mediador do processo de ensino ${ }^{3}$.

Pesquisas mostram que a aprendizagem ativa é uma estratégia de ensino muito eficaz, independentemente do assunto, quando comparada a métodos de ensino tradicionais, como aulas expositivas. Com métodos ativos, os alunos assimilam maior volume de conteúdo, retêm a informação por mais tempo e aproveitam as aulas com mais satisfação e prazer ${ }^{4}$.

Corroborando essa tese, Schwartzman ${ }^{5}$ afirma que as metodologias ativas apresentam-se como possibilidade para a promoção de motivação, interesse, criatividade e autonomia nos alunos, uma vez que se propõem a fortalecer, no educando, sua percepção de que ele mesmo é a origem da própria ação, ao serem apresentadas oportunidades de problematização de situações envolvidas na programação escolar, de escolha de aspectos dos conteúdos de estudo, de caminhos possíveis para o desenvolvimento de respostas ou soluções.

Nas metodologias ativas, o processo de ensino e aprendizagem envolve experiências reais ou simuladas, com objetivo de alcançar e motivar o discente, pois, diante do problema, ele se detém, examina, reflete, relaciona sua história e passa a ressignificar suas descobertas ${ }^{6,7}$.

\section{Objetivo Geral e Específico}

O projeto visou, como objetivo geral, proporcionar um conjunto de atividades baseadas em metodologias ativas, consequentemente, diferenciadas e práticas, com intuito de estimular os alunos a não interromper o processo de aprendizagem, contendo, dessa maneira, a evasão na instituição.

O objetivo específico foi desenvolver habilidades práticas de área específicas ligadas ao curso de mecânica em soldagem da Faculdade de Tecnologia de Pindamonhangaba (FATEC Pindamonhangaba) por meio de oficinas práticas extraclasses, promovendo um momento único de interação entre professores e alunos de diversos semestre no mesmo trabalho para o desenvolvimento das habilidades afins.

\section{PROCESSOS METODOLÓGICOS}

Este trabalho decorre da observação direta dos autores, que também foram professores nas oficinas ministradas; portanto, trata-se de pesquisa-ação, já que os pesquisadores estão envolvidos em todas as etapas.

As oficinas foram oferecidas em agrupamento de quatro turmas por período. Adicionalmente, realizaram-se nos horários de $11 \mathrm{~h} 20$ às 13 horas, nos dias que os alunos não tinham aula nesse período.

A todas as oficinas foram servidos lanches às $11 \mathrm{~h} 20$, que contou com a colaboração dos funcionários, alunos e professores que trabalharam com recursos provindos de doações.

A Tabela 1 lista as oficinas realizadas no $1^{\circ}$ semestre de 2018 com os temas relacionados a cada uma delas e formação do professor responsável, e a Tabela 2 mostra as cargas horárias e distribuição temporal dos respectivos cursos.

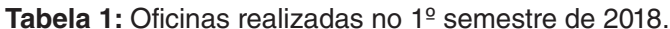

\begin{tabular}{|c|c|}
\hline Oficinas & Professor responsável \\
\hline $\begin{array}{c}\text { Conceitos básicos de soldagem } \\
\text { para utilização de laboratório } \\
\text { Utilização do Laboratório de } \\
\text { química e preparo de soluções }\end{array}$ & $\begin{array}{c}\text { Carlos Eduardo Figueiredo } \\
\text { dos Santos }\end{array}$ \\
\hline Welding terminology & Ana Beatriz R. M. Abrahão \\
\hline $\begin{array}{c}\text { Estudo de software Educativo: } \\
\text { Aprendendo a manipular a } \\
\text { calculadora científica }\end{array}$ & Wiliam Gonzaga Pereira \\
\hline
\end{tabular}

\section{Planejamento (cronograma das oficinas primeiro semestre)}

O planejamento e a execução do cronograma das oficinas ocorreram conforme os dias em que os alunos dos cursos de tecnologia em soldagem e tecnologia em projetos mecânicos saem às 11 h20. A Tabela 2 evidencia o cronograma seguido.

Tabela 2: Carga horária e cronograma das oficinas oferecidas.

\begin{tabular}{|c|c|c|}
\hline Oficinas & Data & $\begin{array}{c}\text { Carga horária } \\
\text { (horas) }\end{array}$ \\
\hline $\begin{array}{c}\text { Conceitos básicos de } \\
\text { soldagem para utilização de } \\
\text { laboratório }\end{array}$ & $\begin{array}{c}\text { Segundas-feiras: } \\
23 \text { de abril, 7, 14 } \\
\text { e } 21 \text { de maio }\end{array}$ & 8 \\
\hline $\begin{array}{c}\text { Utilização do Laboratório } \\
\text { de química e preparo de } \\
\text { soluções }\end{array}$ & $\begin{array}{c}\text { Terças-feiras: } \\
24 \text { de abril, 8, 15 } \\
\text { e 22 de maio }\end{array}$ & 6 \\
\hline $\begin{array}{c}\text { Terminologia de soldagem } \\
\text { em inglês }\end{array}$ & $\begin{array}{c}\text { Quartas-feiras: } \\
25 \text { de abril, 16 e } \\
29 \text { de maio }\end{array}$ & 6 \\
\hline $\begin{array}{c}\text { Estudo de software educativo: } \\
\text { Aprendendo a manipular a } \\
\text { calculadora científica }\end{array}$ & $\begin{array}{c}\text { Sextas-feiras: } 27 \\
\text { de abril, 4, 11 e } \\
18 \text { de maio }\end{array}$ & 8 \\
\hline
\end{tabular}




\section{Descrições das oficinas oferecidas do primeiro semestre}

As descrições das oficinas oferecidas seguem a ficha de inscrição para aprovação pela Câmara de Ensino, Pesquisa e Extensão (Cepe) e Congregação. Os itens a seguir mostram exatamente como foi apresentado e aprovado pela CEPE e as figuras ilustram momentos registrados nas aulas.

\section{Conceitos básicos de soldagem para utilização de laboratório}

Objetivo: introduzir os alunos ao Laboratório de soldagem e conscientizá-los do seu funcionamento para melhor eficiência e utilização futura.

Método: aula teórica e aulas práticas de soldagem em SMAW, GMAW, GTAW, FCAW e SAW.

Carga horária: 8 horas.

Conteúdo: 2 horas de aula teórica para apresentação dos processos e 6 horas de aulas práticas (preparação dos equipamentos e consumíveis e soldagem para aprendizagem do controle do arco elétrico).

Recursos utilizados: apostila eletrônica fornecida pelo Prof. e fontes de soldagem do Laboratório de soldagem (eletrodos revestidos, arames de soldagem e sucata de chapas).

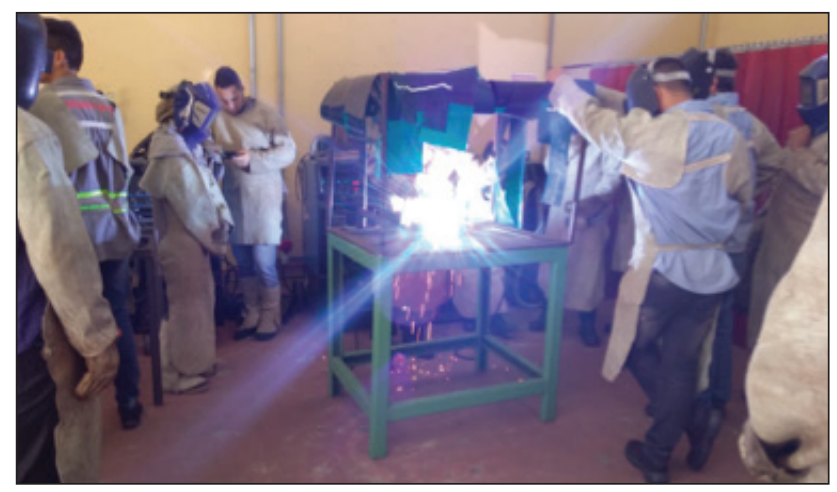

Figura 1: Aula prática no laboratório da oficina do Prof. Carlos Eduardo Figueiredo dos Santos.

\section{Utilização do Laboratório de química e preparo de soluções}

Objetivo: ensinar os alunos a utilizar o laboratório de químico com eficiência e segurança.

Método: aulas teóricas e práticas

Carga horária: 6 horas

Conteúdo: noções gerais e apresentação das normas e regras de segurança para utilização do laboratório químico; preparo e manuseio de soluções para o ataque químico; descarte de reagentes químicos e limpeza de vidraria; noções gerais dos equipamentos do laboratório; prática em dupla para preparo de solução, abordando todas as etapas anteriores.

Recursos utilizados: emissão de apostila, certificado para os participantes (20 participantes) e todos os recursos disponíveis no laboratório químico.

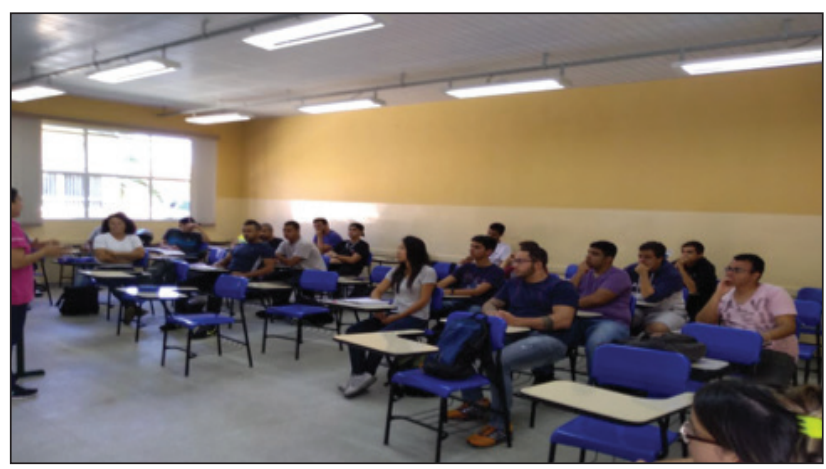

Figura 2: Aula teórica da oficina de utilização do laboratório químico e preparo de soluções.

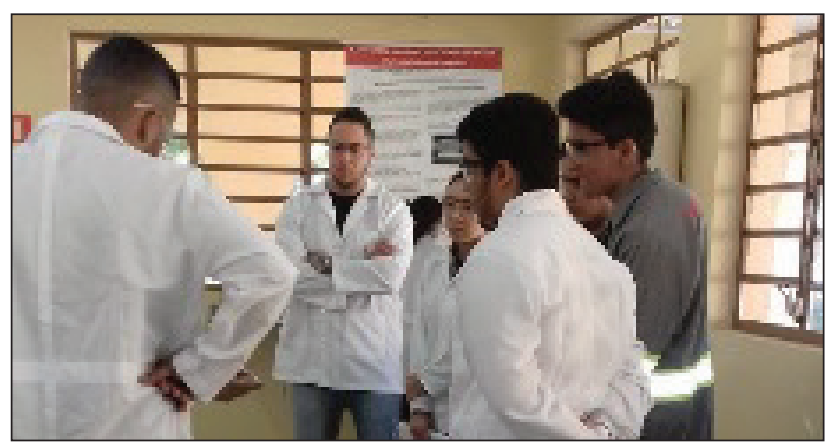

Figura 3: Aula prática da oficina de utilização do laboratório químico e preparo de soluções.

\section{Welding terminology}

Objetivos: promover aos alunos o conhecimento da terminologia de soldagem em língua inglesa e sua pronúncia e produzir um glossário ilustrado dessa terminologia.

Método: aulas expositivas e práticas com pesquisa em websites específicos da área de soldagem e dicionários técnicos. Para pronúncia, gravação em áudio da terminologia.

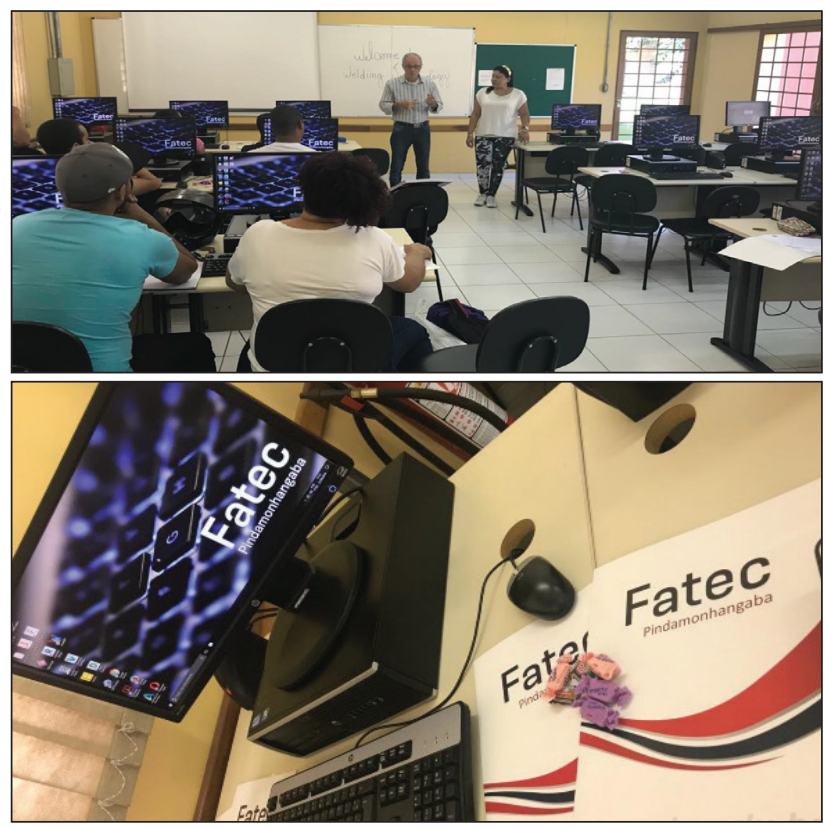

Figura 4: Oficina welding terminology. 
Carga horária: 6 horas.

Conteúdo: terminologia de soldagem em inglês.

Recursos utilizados: computadores e apostilas.

\section{Estudo de software educativo: Aprendendo a manipular a calculadora científica}

Objetivo: ensinar aos alunos os diversos tipos de comandos e funções da calculadora científica e aplicá-los à resolução de problemas concretos de sala de aula e laboratório.

Método: aulas expositivas com apresentação no PowerPoint, utilização de apostila e manuseio prático da calculadora científica.

Carga horária: 8 horas.

Conteúdo: comandos básicos da calculadora científica (manual e apostila), resolução de problemas utilizando os comandos de álgebra e estatística.

Recursos utilizados: calculadora científica, apostila, data show e sala de aula.

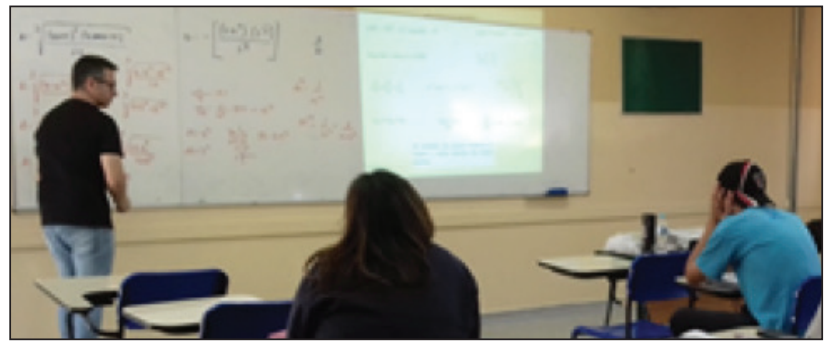

Figura 5: Alunos e Prof. responsável pela oficina de manipulação de calculadora científica.

\section{RESULTADOS E AVALIAÇÃO}

A proposta desse projeto é oferecer aos alunos oficinas técnicocientíficas e teve como objetivo conter a evasão desses por meio de atividades diferenciadas baseadas em metodologias ativas que visam a sanar suas dificuldades primárias com a utilização da calculadora científica para compilação de dados estáticos e outros,

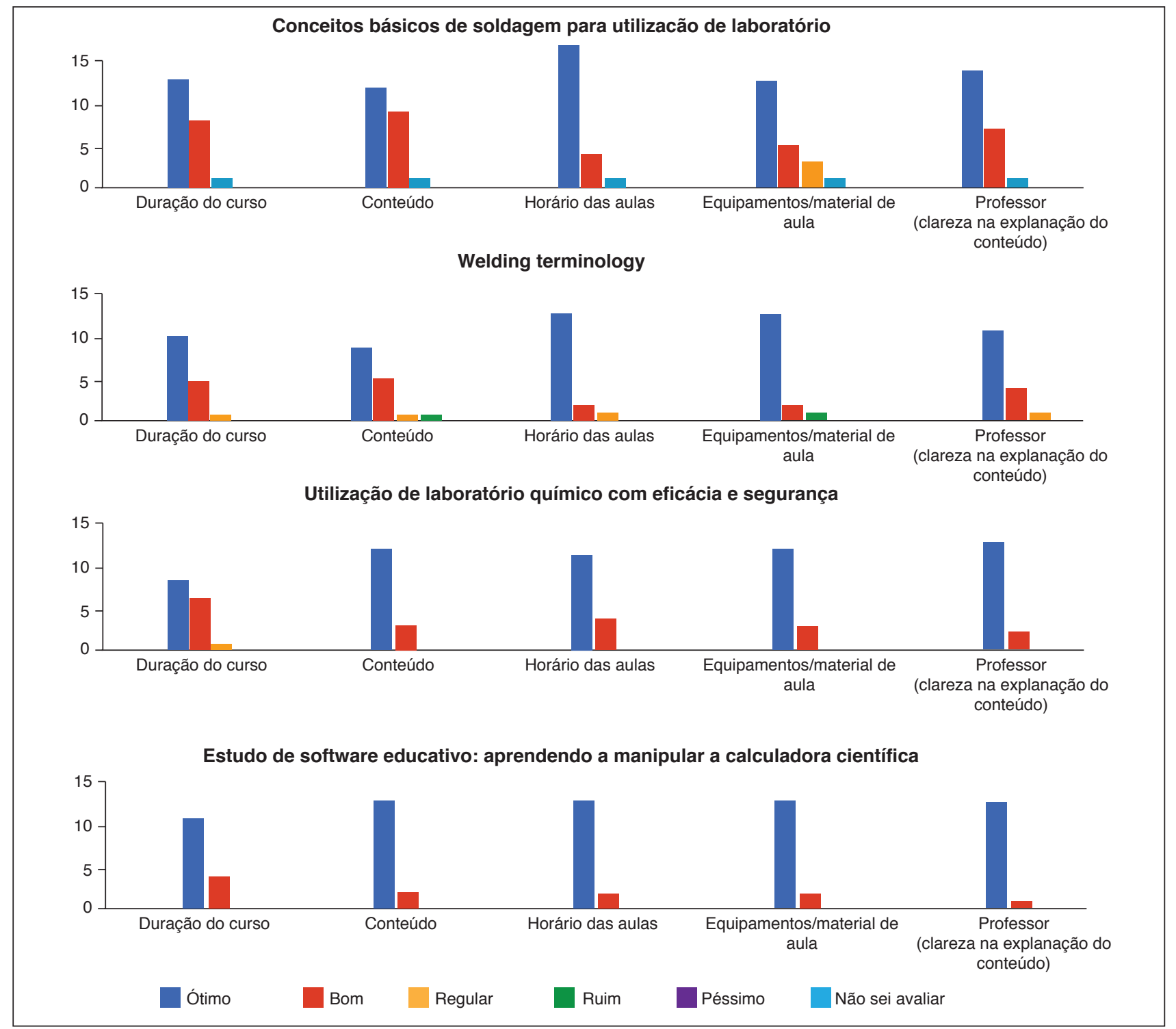

Figura 6: Relatório de pesquisa de satisfação - Oficinas técnico-científicas - 1ํs semestre de 2018. 
assim com o inglês técnico, que facilitaria a compreensão de uma língua específica desse nicho (engenharia mecânica com ênfase em soldagem). Os alunos receberam a proposta com entusiasmo e participaram efetivamente. Ao final das oficinas, os alunos responderam a um questionário de satisfação que revelou pontos muito positivos, como mostrado na Fig. 6.

\section{CONCLUSÕES E CONSIDERAÇÕES FINAIS}

A proposta principal deste projeto foi promover motivação apostando em atividades que revelam a participação ativa dos alunos, visto que as atividades desenvolvidas foram práticas, extraclasses e de curta duração.

Os alunos aprenderam, de maneira diferenciada, conceitos que na sala de aula são apresentados, muitas vezes, apenas na teoria, devido ao tempo escasso das disciplinas. Vale ressaltar que as oficinas não associam o aluno às notas, desvinculando-os do encargo que elas representam. Dessa maneira, as aulas procederam numa atmosfera de estar presente por opção, estar presente por motivação, fator intrínseco que beneficia o processo de aprendizagem, tornando o processo de ensinar e aprender efetivo e significativo.

A equipe organizadora contou com a participação de alunos e teve apoio de alunos e professores envolvendo de maneira geral a FATEC Pindamonhangaba.
Enfim, com os resultados das avaliações feitas pelos próprios participantes das oficinas, pôde-se comprovar que realmente obtiveram-se resultados satisfatórios em relação à proposta deste projeto.

\section{REFERÊNCIAS}

1. Ministério da Educação. Secretaria de Educação Média e Tecnológica (BR). Orientações curriculares para o ensino médio: ciências da natureza, matemática e suas tecnologias. Brasília: Mec; 2006.

2. Ministério da Educação. Secretaria de Educação Média e Tecnológica (BR). Parâmetros curriculares nacionais. Brasília: $\mathrm{Mec} ; 2000$

3. Moura I, Satiko D. Matemática (ideias e desafios) - 5a série. 9a ed. São Paulo: Saraiva; 2000

4. Druk S. O drama do ensino da matemática. Folha de São Paulo. mar 2003.

5. Schwartzman S. Erros que se repetem, educação, São Paulo, Brasil. Jan 2007. 117:4-6.

6. Salomão A. Muito dinheiro para pouco resultado, Exame 30 set 2006. 877:28-30.

7. Salomão A. O preço da ignorância, Exame 26 set 2006. 877:20. 